\title{
TITLE:
}

\section{Chemistry in heterocyclic ammonium fluorohydrogenate room-temperature ionic liquid}

$\operatorname{AUTHOR}(S)$ :

Tsuda, Tetsuya; Hagiwara, Rika

\section{CITATION:}

Tsuda, Tetsuya ... [et al]. Chemistry in heterocyclic ammonium fluorohydrogenate roomtemperature ionic liquid. Journal of Fluo rine Chemistry 2008, 129(1): 4-13

\section{ISSUE DATE:}

2008-01

URL:

http://hdl.handle.net/2433/251200

\section{RIGHT:}

(c) 2007. This manuscript version is made available under the CC-BY-NC-ND 4.0 license

http://creativecommons.org/licenses/by-nc-nd/4.0/; The full-text file will be made open to the public on 1 January 2010 in accordance with publisher's 'Terms and Conditions for Self-Archiving'., この論文は出版社版でありません。引用の際 には出版社版をご確認じ利用ください。; This is not the published version. Please cite only the published version. 


\section{Chemistry in Heterocyclic Ammonium Fluorohydrogenate Room-Temperature}

\section{Ionic Liquid}

Tetsuya Tsuda ${ }^{a^{*}}$, Rika Hagiwarab

${ }^{a}$ Department of Chemistry and Biochemistry, The University of Mississippi, University, Mississippi 38677-1848, USA

bDepartment of Fundamental Energy Science, Graduate School of Energy Science, Kyoto University, Sakyo-ku, Kyoto 606-8501, Japan

*Corresponding author.

Phone number: +1-662-915-7605; Fax number: +1-662-915-7300.

E-mail address: ttsuda@olemiss.edu. 


\section{Abstract}

Investigation on alkali fluoride-HF system has been initiated in the $19^{\text {th }}$ century. The technique is currently utilized in fluorine-chemical industry. But, the problem is that this system readily releases hazardous HF. Although organic base, e.g., amine, with HF, which is mainly applied to fluorination treatment for organic compound, reduces the HF release, the solution still requires careful handling because of limited amount of free HF. Recently family of fluorohydrogenate room-temperature ionic

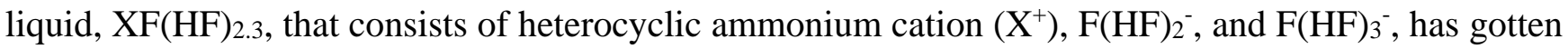
a lot of attentions due to the interesting physicochemical properties such as negligible vapor pressure $(<$ $7.5 \times 10^{-3}$ torr $(=1 \mathrm{~Pa})$ at $\left.298 \mathrm{~K}\right)$, high conductivity, and low corrosiveness. This novel solvent will greatly contribute to development of fluorine chemistry. In this article, fundamental techniques and physicochemical data on the fluorohydrogenate RTIL are summarized, and molecular science in the dialkylimidazolium fluorohydrogenates leading to the understanding of the unusual properties is reviewed based on recent experimental and theoretical considerations.

Keywords: ionic liquids; fluorides; structure elucidation; computer chemistry; x-ray diffraction. 


\section{Introduction}

We suppose that most chemists and engineers knew a new noun "room-temperature ionic liquid (RTIL)” or its simple form "ionic liquid” in the past decade. But, surprisingly, RTIL, which was formerly known by "room-temperature molten salt (RTMS)”, has a long history of almost a hundred years. There is good evidence that the first RTMS/RTIL was identified and characterized by Walden in 1914, who examined the electrical conductivity of ethylammonium nitrate [1]. Today a literature search with SciFinder Scholar (online Chemical Abstracts system) employing the keywords "roomtemperature ionic liquid" or "ionic liquid" displays thousands of articles. Scientific interest in these liquids continues to grow exponentially. Compared with “modern” RTIL having fluoroanions such as $\mathrm{BF}_{4}^{-}, \mathrm{PF}_{6}{ }^{-}, \mathrm{N}\left(\mathrm{SO}_{2} \mathrm{CF}_{3}\right)_{2}^{-}\left(=\mathrm{NTf}_{2}{ }^{-}\right)$, and $\mathrm{CF}_{3} \mathrm{SO}_{3}{ }^{-}\left(=\mathrm{TfO}^{-}\right)$, “classic” RTIL, which is composed of an anhydrous metal halide combined with an heterocyclic aromatic halide, e.g., $\mathrm{AlCl}_{3}-1$-ethyl-3methylimidazolium chloride (EtMeImCl) and $\mathrm{AlCl}_{3}$-1-(1-butyl)pyridinium chloride (BuPyCl), exhibit relatively low viscosity and high conductivity, but is highly sensitive to moisture, i.e., not air-stable, especially at higher Lewis acidity [2]. Figure 1 shows photographs of three Pyrex test tubes containing different types of RTILs before and after the intentional addition of water. Included in this figure are a classical moisture-reactive RTIL, 60.0-40.0 mol \% $\mathrm{AlCl}_{3}-\mathrm{EtMeImCl}$; an air stable hydrophilic RTIL, EtMeImF(HF)2.3; and a hydrophobic tri- $n$-butylmethylammonium bis((trifluoromethyl)sulfonyl)imide, $n$-BusMeNNTf2. The appearance of each RTIL before the addition of water is shown in the top picture. The addition of water to an open test tube of the Lewis acidic $\mathrm{AlCl}_{3}-\mathrm{EtMeImCl}$ results in a violent reaction with the evolution of heat and $\mathrm{HCl}$ gas and an obvious change in the appearance of the RTIL (Fig. 1, bottom picture). This problematic property has prevented the development of chloroaluminate RTIL studies. In contrast, the addition of water to EtMeImF(HF)2.3 and $n$-Bu3MeNNTf2 results in no obvious chemical change. 
A large number of "modern” RTILs have been reported in the literatures since discovery of airstable RTIL by Drs. Wilkes and Zaworotko in 1992 [3], but unfortunately there are only a limited number of RTILs that are really suitable for doing chemistry. This is because most exhibit high viscosity (> $100 \mathrm{cP}$ ). However, some have both features of air-stable and low viscosity. Relatively speaking, the combination of imidazolium- or sulfonium-based cations and complex anions having plane structure such as $\mathrm{N}(\mathrm{CN})_{2}{ }^{-}, \mathrm{C}(\mathrm{CN})_{3}{ }^{-}$, or $\mathrm{F}(\mathrm{HF})_{2.3^{-}}\left(\mathrm{F}(\mathrm{HF})_{2.3^{-}}\right.$is made up of $70 \% \mathrm{~F}(\mathrm{HF})_{2}{ }^{-}$and $30 \%$ $F(H F) 3^{-}$.) results in RTILs with low viscosity and good air-stability or hydrophobicity. For the readers' reference, we have given several excellent monographs [4] and review articles [5] that describe the synthesis, purification, and physicochemical properties of RTILs.

Anhydrous HF solution with inorganic [6] and organic chemicals [7] has been applied to fluorinechemical engineering as an alternative to toxic and corrosive neat HF liquid (boiling point: ca. $293 \mathrm{~K}$ ) with high vapor pressure. The history initiated in the $19^{\text {th }}$ century, and the first liquid was KF-HF [8]. The phase diagram (Fig. 2) was determined with a specialized apparatus in the 1930’s [9]. The liquid salt is still utilized commercially for $\mathrm{F}_{2}$ gas production. As to fluorination reactions of organic compounds, in many cases, less volatile solution composed of anhydrous HF and organic bases such as amine are employed as shown in Fig. 3 [10]. For the complete details of this procedure the reader should consult the original literature cited in reference 7f. We know non-heterocyclic ammonium fluorohydrogenates are also interesting liquids [11,12], but these melts slightly release hazardous HF at room temperature. On the other hand, fluorohydrogenate RTIL, XF(HF)2.3, consisting of heterocyclic ammonium cation $\left(\mathrm{X}^{+}\right), \mathrm{F}(\mathrm{HF}) 2^{-}$, and $\mathrm{F}(\mathrm{HF}) 3^{-}$have unusual physicochemical properties such as negligible vapor pressure $\left(<7.5 \times 10^{-3}\right.$ torr $(1 \mathrm{~Pa})$ at $\left.298 \mathrm{~K}\right)$, high conductivity, low viscosity, and low corrosiveness. This novel solvent will bring fluorine chemistry closer to scientists and engineers. In this article, molecular science in the dialkylimidazolium fluorohydrogenates leading to the understanding of the interesting properties is typically reviewed, and preparation method and physicochemical data for the $\mathrm{XF}(\mathrm{HF})_{2.3}$ are also given. 


\section{Physicochemical properties of fluorohydrogenate RTIL}

Melting points of conventional inorganic and organic HF salts are summarized in Table 1. All salts show that the melting point decreases as number of HF ligand, $n$, increases. The larger $n$ values make low viscosity, but the vapor pressure increases with the value because of presence of free HF in the melts. Compared with these conventional salts, fluorohydrogenate RTIL, which consists of heterocyclic ammonium cation, $\mathrm{F}(\mathrm{HF})_{2}{ }^{-}$, and $\mathrm{F}(\mathrm{HF})_{3}{ }^{-}$, contains no free $\mathrm{HF}$ in the solution. Basic structures of the cations are shown in Fig. 4 along with the anions calculated by ab initio molecular orbital calculation [14]. Although these two anions can be determined by spectroscopic methods, nuclear magnetic resonance analysis cannot make a distinction between the anions due to rapid HF exchange reaction [15].

$$
\mathrm{F}(\mathrm{HF}) 2^{-}+\mathrm{F}(\mathrm{HF}) 3^{-} \rightleftarrows \mathrm{F}(\mathrm{HF}) 3^{-}+\mathrm{F}(\mathrm{HF}) 2^{-}
$$

This rapid HF exchange reaction likely relates to some anomalous properties of this RTIL system such as negligible vapor pressure and no obvious Pyrex glass etching.

Physicochemical properties of the fluorohydrogenate RTILs are summarized in Table 2. All the melting points show below $273 \mathrm{~K}$. As expected, the density decreases with increase in volume of the cation. Figure 5 exhibits Walden plot constructed from Table 2. It seems to be unable to approximate by one linear function. However, what is interesting is that the plot can be expressed by several linear functions when the RTIL is classified according to the basic cation structures. This may be because dissociation degree in the RTIL and aggregated ionic species vary with the cation structures [14]. In fact, Walden plot for EtMeIm-based RTILs having fluoroanions shows a good linear function independent of the anionic species including $F(H F) 2.3^{-}$(Fig. 5 (inset)). 
It is important to evaluate ratio of charge carrier that is called transport number, because it helps for us to speculate the conduction mechanism. In the RTIL system, the transport number was formerly estimated by means of moving boundary (MB) method [21] or modified Hittorf (MH) method [22-24], but now a popular way to know the number is pulsed gradient-field spin-echo NMR (PGSE-NMR) method $[14,25,26]$. The former is mainly used for "classic" RTILs, $\mathrm{AlCl}_{3}-\mathrm{EtMeImCl}$ or $\mathrm{AlBr}_{3}-$ EtMeImBr, and the latter is applied to "modern" RTILs. With regard to the MB method, the transport number for EtMeIm ${ }^{+}$in haloaluminate RTILs, $\mathrm{AlX}_{3}-\mathrm{EtMeImX}$ [X: $\mathrm{Cl}$ or $\mathrm{Br}$ ], is calculated from

$$
t_{\mathrm{EtMeIm}^{+}}=1-t_{\mathrm{AlX}_{4}^{-}}=1-\frac{\pi r^{2} \Delta h \rho / \mathrm{M}}{Q / \mathrm{F}}
$$

where $t_{\mathrm{EtMeIm}}{ }^{+}$and $t_{\mathrm{AlX} 4^{-}}$is transport number for the EtMeIm${ }^{+}$and the $\mathrm{AlX}_{4}^{-}$, respectively, $r$ is the capillary radius, $\rho$ is the density of the RTILs, $\Delta h$ is the distance traveled by the boundary, M is the molecular weight of the RTILs, F is the Faraday constant, $Q$ is the number of passed charge. For the MH method, the value in the haloaluminate RTILs is assessed by using a following expression for anode compartment

$$
t_{\mathrm{EtMeIm}^{+}}=\frac{\mathrm{F}}{Q}\left[\frac{\left(1-x^{b}{ }_{\mathrm{Al}}\right) w^{b}}{x^{b}{ }_{\mathrm{Al}} \mathrm{M}_{\mathrm{AlX}_{3}}+\left(1-x^{b}{ }_{\mathrm{Al}}\right) \mathrm{M}_{\mathrm{EtMelmX}}}-\frac{\left(1-x^{a}{ }_{\mathrm{Al}}\right) w^{a}}{x^{a}{ }_{\mathrm{Al}} \mathrm{M}_{\mathrm{AlX}_{3}}+\left(1-x^{a}{ }_{\mathrm{Al}}\right) \mathrm{M}_{\mathrm{EtMeImX}}}\right]
$$

where $x_{\mathrm{Al}}$ and $\mathrm{M}_{\mathrm{AlX} 3}$ is molar fraction and formula weight of $\mathrm{AlX}_{3}$ in the RTILs, respectively, $w$ is the weight of the RTILs used in the measurement. The superscript $a$ and $b$ denotes the condition after and before the experiments, respectively. As regards the PGSE-NMR, the value is estimated from these two equations 


$$
\begin{aligned}
& E(g, \delta, \Delta)=\frac{S}{S_{g=0}}=\exp \left\{-\gamma^{2} g^{2} \delta^{2} D[\Delta-(\delta / 3)]\right\} \\
& t_{i}=\frac{Z_{i} c_{i} D_{i}}{\sum z_{j} c_{j} D_{j}}
\end{aligned}
$$

where $S$ is the spin-echo signal intensity, $\delta$ is the duration of the field gradient with magnitude, $g, \gamma$ is the gyromagnetic ratio, $\Delta$ is the interval between the two gradient pulses, $z$ is the valence of the ion, $c$ is the concentration, subscript $i$ and $j$ represent ionic species, and $D$ is the diffusion coefficient derived from equation (4), which is a standard equation to estimate the self-diffusion coefficients.

Whereas traditional MB and MH techniques are that the driving force is voltage gradient, the recent technique is that the force is pulsed field gradient. Therefore we cannot compare the data rigorously. Especially in high viscous RTILs, the deviation will be getting larger because mobility of the ions is restricted in such RTILs, i.e., the ions cannot respond to rapid change in the pulsed field gradient. Here, only the transport numbers for the cation, $t_{\text {EtMeIm }}{ }^{+}$, in EtMeIm ${ }^{+}$-based RTILs having relatively low viscosity are summarized in Table 3. The main charge carrier in the RTILs should be the EtMeIm ${ }^{+}$ cation except EtMeImF(HF) 2.3. The $t_{\mathrm{EtMeIm}}{ }^{+}$diminishes in the following order: bromoaluminate anion \left.${\left(t_{\mathrm{EtMeIm}}\right.}^{+}=0.76\right)$, chloroaluminate anion $(0.71)$, fluoroanion $(0.5 \sim 0.64)$, fluorohydrogenate anion $(0.44$ $\sim 0.49$ ). The differences between the haloaluminate anions imply that the halides in the anions affect the transport numbers. However, further investigation is required to discuss the variation with unerring precision.

It is well-known that physicochemical property of "classic" RTIL composed of anhydrous metal halide combined with organic halide drastically changes with the metal halide composition $[2,28]$. Also, the physicochemical property of EtMeImF(HF) $n$ can be controlled by the number of HF ligand, 
like $\mathrm{AlCl}_{3}$-EtMeImCl. At higher $n$ value, the following equilibrium reaction readily proceeds to the right. And then, the solution enables to release HF.

$$
\mathrm{F}(\mathrm{HF})_{n}^{-} \rightleftarrows \mathrm{F}(\mathrm{HF})_{n-1}{ }^{-}+\mathrm{HF}
$$

It follows that the HF dissociation becomes harder as $n$ decreases. Eventually the $n$ value for the fluorohydrogenated-heterocyclic RTILs converges on 2.3 if the vapor pressure reaches $7.5 \times 10^{-3}$ torr (= $1 \mathrm{~Pa})$ at $298 \mathrm{~K}$. However, further $\mathrm{HF}$ release is possible under vacuum heating. The further HF

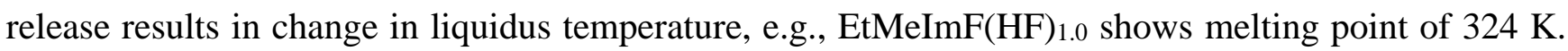
A phase diagram of the $\operatorname{EtMeImF}(\mathrm{HF})_{n}[1.0 \leq n<2.6]$ was constructed by adding HF to the EtMeImF(HF) 1.0 (Fig. 6) [18]. Figure 7 exhibits conductivity for the EtMeImF(HF) $n[1.3<n \leq 2.3]$ at $298 \mathrm{~K}$. The behavior is similar to conventional HF melts as given in Table 2, not "classic" $\mathrm{AlX}_{3}-$ EtMeImX (X: $\mathrm{Cl}$ or $\mathrm{Br}$ ) RTIL systems that show maximum value at 50 mol \% $\mathrm{AlX}_{3}$, i.e., $n=1.0$ $\left(\mathrm{EtMeImX}\left(\mathrm{AlX}_{3}\right)_{1.0}\right)$ [29].

Recently, Arrhenius plot of the self-diffusion coefficients for the $\mathrm{F}(\mathrm{HF}) n^{-}[n: 1,2$, or 3$]$ in the EtMeImF $(\mathrm{HF})_{n}$ have been constructed by using molecular dynamic simulation [27]. As shown in Fig. 8, the self-diffusion coefficients for the $\mathrm{F}(\mathrm{HF})_{n}{ }^{-}$species become faster with increase in the $n$ value. This molecular dynamics calculation supports experimental results shown in Fig. 7. The reason is described in the following section.

\section{Liquid structure in 1-alkyl-3-methylimidazolium fluorohydrogenates}

Figures 9 and 10 depict single crystal structure of EtMeImF(HF)1.0 that was grown at room temperature from HF-deficient RTIL prepared by a vacuum drying of EtMeImF(HF)2.3 at ca. $400 \mathrm{~K}$ [30]. A molecular configuration used in this article is exhibited in Fig. 11. The X-ray diffraction 
reveals that the single crystal has a layered structure and that all the cations and anions exist in the same plane except the hydrogen atoms on the side chains (Fig. 9). The interlayer distance is very close to van der Waals distance between common aromatic graphite carbon layers. It suggests that the interaction between two imidazolium rings is very weak. Geometric parameter for the EtMeIm ${ }^{+}$cation is almost the same as previous articles except absence of any torsion of C2-N1-C6-C7 bond [30]. In addition, stacked EtMeIm ${ }^{+}$cations make a pillar along the $b$-axis (Fig. 10). The interaction, which consists of both usual coulomb interaction and unusual hydrogen bonding having not strong direction dependence, between $\mathrm{H} 4$ hydrogen and $\pi$ electrons of the nearest other cation compensates the cationcation repulsion. This would be the reason that the cationic planes show van der Waals-like distance of $3.38 \AA$. The $\mathrm{F}(\mathrm{HF})_{1}{ }^{-}$anions are also stacked along the $b$-axis and the anions are sandwiched in between the ethyl groups on the EtMeIm ${ }^{+}$cations. The structure reduces the anion-anion repulsion. As shown in Fig. 11, F1 that represents one fluorine of $\mathrm{F}(\mathrm{HF})_{1}{ }^{-}$anion interacts with $\mathrm{H} 2^{\mathrm{i}}$ and $\mathrm{H} 4$, and $\mathrm{F} 2$ has an interaction with $\mathrm{H}^{\mathrm{ii}}{ }^{\mathrm{i}}$. That is, the $\mathrm{F}(\mathrm{HF})_{1}{ }^{-}$anion makes three interacting bonds to three different cations because those bond distances are clearly shorter than expected from the sum of van der Waals radii of 1.20 and $1.47 \AA$ for hydrogen and fluorine atoms, respectively [31]. F $\cdots$ H bond distances are $1.951 \AA$ for $\mathrm{F} 1 \cdots \mathrm{H} 2^{\mathrm{i}}, 2.166 \AA$ for $\mathrm{F} 1 \cdots \mathrm{H} 4$, and $2.226 \AA$ for $\mathrm{F} 2 \cdots \mathrm{H} 5^{\mathrm{ii}}$. The specific interaction has already been discussed in chloroaluminate RTILs and EtMeImCl by using FTIR [32]. Usually C-H stretches at the C2, C4, and C5 sites and those in the alkyl side chains appear at $3100 \sim 3200 \mathrm{~cm}^{-1}$ and $2900 \sim 3000$ $\mathrm{cm}^{-1}$, respectively. In the Lewis basic chloroaluminate $\mathrm{RTIL}\left(\mathrm{AlCl}_{3}<50.0 \mathrm{~mol} \%\right.$ ) containing free $\mathrm{Cl}^{-}$, the former band shifts to $3000 \sim 3100 \mathrm{~cm}^{-1}$ because the strong base, $\mathrm{Cl}^{-}$, makes strong interaction at the sites. The bonding is considerably weakened in the Lewis acidic $\mathrm{AlCl}_{3}$-EtMeImCl RTIL. Similar behavior is observed in EtMeImF(HF)n; that is, such peak shift is not observed in the Lewis acidic EtMeImF(HF)2.3, but the EtMeImF(HF)1.0 shows [30]. Molecular dynamics simulation also indicates the same result [33]. Thus, the negligible interacting bond in the EtMeImF(HF)2.3 most likely make the diffusion of Lewis acidic anions, $\mathrm{F}(\mathrm{HF}) 2^{-}$and $\mathrm{F}(\mathrm{HF}) 3^{-}$, faster as exhibited in Fig. 8. 
Liquid structure of 1-alkyl-3-methylimidazolium fluorohydrogenates, RMeImF(HF)2.3, has been examined by high-energy synchrotron X-ray diffraction experiments [34,35] and molecular dynamics simulation [33]. Figure 12 shows the total correlation functions, $T(r)$, for the RMeImF(HF) 2.3 from the synchrotron XRD. Correlation peaks at around $1.0 \AA$ correspond to $\mathrm{C}-\mathrm{H}$ bonds in the alkylimidazolium cation. The intensity is enhanced as the alkyl chain is lengthened. At $1.4 \AA$, remarkable peaks appear due to the $\mathrm{C}-\mathrm{C}$ and $\mathrm{C}-\mathrm{N}$ bonds in the imidazolium ring and alkyl groups. These peaks for the RTILs having longer alkyl group slightly shift to higher $r$ since average C-C bond length in the alkyl group is longer than that in the imidazolium ring. The correlation of second neighbor C-C [C2-C5, C2-C4], C-N [C4-N1, C5-N3], and N-N [N1-N3] in the imidazolium ring appears at $2.2 \AA$ (The configuration is indicated in Fig. 11.). The peaks at ca. $2.5 \AA$ show the second neighbor C-C [C2-C6, C2-C8, C5-C6, C4-C8] and N-C [N1-C7] correlations between the imidazolium ring and alkyl groups. Unfortunately, the peak from F-F correlation for the $\mathrm{F}(\mathrm{HF}) 2^{-}$and $\mathrm{F}(\mathrm{HF}) 3^{-}$anions overlaps with aforementioned peaks. The peaks observed at ca. $3.6 \AA$ are due to the correlation of $\mathrm{C}$ atom in the alkyl group and third neighbor $\mathrm{C}$ or $\mathrm{N}$ atom in the imidazolium ring [C2-C7, C5-C7, C5-C8, C4-C6, N1-C8, N3-C6]. Given that layer separation in solid EtMeImF(HF) 1.0 $_{10} 3.38 \AA$ [30] and the $T(r)$ function for EtMeImF(HF) 2.3 RTIL is quite similar to molten EtMeImF(HF) ${ }_{1.0}$ [35], it is highly likely that the peaks at ca. $3.4 \AA$ correspond to the layer separation in the RTILs. Salanne et al. have examined molecular structure in the EtMeImF(HF)2.3 by employing molecular dynamics simulation [33]. They concluded that stacked structure partially exists in the EtMeImF(HF)2.3 from threedimensional plot of imidazolium distribution depicted by the simulation (Figure 13) and that there is no strong interaction between the cation and the anion in the RTIL.

\section{Preparation method for fluorohydrogenate RTIL}


Fluorohydrogenate RTILs, $\mathrm{XF}(\mathrm{HF}) n$, are produced from organic halides with heterocyclic ring and anhydrous HF. Here, we focused only on 1-ethyl-3-methylimidazolium fluorohydrogenate (EtMeImF(HF)2.3) because other fluorohydrogenated RTILs can be prepared by the similar method. In addition, we also describe synthesis and purification methods for 1-ethyl-3-methylimidazolium chloride (EtMeImCl) that is employed as a staring material for the RTIL.

\subsection{1-Ethyl-3-methylimidazolium chloride (EtMeImCl)}

Very frequently, EtMeImCl is selected as a starting material for synthesizing RTILs due to the EtMeIm $^{+}$cation leading to low viscosity and high conductivity. The synthesis and purification methods were established by Wilkes et al. more than two decades ago [36]. But, the techniques seem to be still highly important to prepare high-grade imidazolium-based RTILs.

The EtMeImCl is yielded by condensing ethyl chloride into a corrosion-resisting pressure vessel (or autoclave) containing distilled 1-methylimidazole and acetonitrile. The mixture is heated at $333 \mathrm{~K}$ with stirring continually until the solution shows milky white if the stirring is halted. The unreacted ethyl chloride is ejected by a dry $\mathrm{N}_{2}$ gas flow, followed by evacuating the residual solution until ivorycolored crystal, which is unpurified EtMeImCl, comes out. The crystal can be purified by recrystallization using dry acetonitrile and ethyl acetate. The EtMeImCl dissolves shortly in the acetonitrile of $333 \mathrm{~K}$. After cool-down of the solution, addition of the ethyl acetate results in precipitation of white crystal that is purified EtMeImCl. The procedure is usually repeated at least three times. After heating the pure salt at $373 \mathrm{~K}$ in the dry $\mathrm{N}_{2}$ filled glove box, the fused salt is degassed under vacuum $\left(1 \times 10^{-3}\right.$ torr $)$ because of removing residual ethyl acetate and minimal water contaminant. These whole procedures must conduct using airtight glasswares and a vacuum line (or an inert dry gas filled glove box) to prevent contaminants such as atmospheric moisture because this salt is extremely hygroscopic. 


\subsection{1-Ethyl-3-methylimidazolium fluorohydrogenate $\left(\mathrm{EtMe} \operatorname{ImF}(\mathrm{HF})_{2.3}\right)$}

If one has skills on fluorine chemistry, he or she can prepare high purity EtMeImF(HF)2.3 from EtMeImCl with relative ease. But if not, you have to do this under direction of professionals in fluorine chemistry because this reaction uses a very toxic and corrosive anhydrous HF. Figure 14 depicts a diagrammatic illustration of a vacuum line for the synthesis. As you know, anhydrous HF reacts with glassware violently. Therefore, the line and the reaction cell are made of non-corrosive materials such as SUS-316, FEP (fluoroethylene-propylene copolymer), PFA (perfluoroalkoxide polymer), and Teflon. The anhydrous $\mathrm{HF}$, which was stored in a cell with $\mathrm{K}_{2} \mathrm{NiF}_{6}$ overnight to completely eliminate water, is used for the reaction with EtMeImCl in a FEP tube with a Teflon-coated stirring bar. The large excess anhydrous HF is condensed in the tube connected to the anhydrous HFfilled vacuum line by cooling the tube with liquid $\mathrm{N}_{2}$. Generated $\mathrm{HCl}$ gas is immediately eliminated by evacuation. This procedure should be repeated several times not to leave any unreacted $\mathrm{Cl}^{-}$in the RTIL. Unreacted anhydrous HF is eliminated from the resulting solution by the use of a rotary pump through chemical traps and a cold trap. This procedure is continued until the vapor pressure reaches $7.5 \times 10^{-3}$ torr $(=1 \mathrm{~Pa})$ at $298 \mathrm{~K}$. The remaining liquid is $\operatorname{EtMeImF}(\mathrm{HF})_{2.3 .}$. If the $\operatorname{EtMeImF}(\mathrm{HF})_{2.3}$ is treated with $\mathrm{MF}_{x}\left[\mathrm{M}: \mathrm{B}(x=3) ; \mathrm{P}, \mathrm{As}, \mathrm{Nb}, \mathrm{Ta}(x=5) ; \mathrm{W}(x=6)\right.$.], the RTIL is converted to EtMeImMF $F_{x+1}$ with volatile HF [37].

\section{Concluding remarks}

Some of the organoheterocyclic cations combined with fluorohydrogenate anions give low viscous, highly conductive room-temperature ionic liquids. The stability of fluorohydrogenate anions in these RTILs are significantly improved compared to conventional fluorohydrogenate salts such as $\operatorname{CsF}(\mathrm{HF})_{n}$ 
and $\mathrm{NH}_{4} \mathrm{~F}(\mathrm{HF})_{n}$. These features seem to be owing to the cation-anion interactions strongly affected by their shapes causing ordered structures in the liquids state. Further studies by high energy x-ray and neutron diffraction experiments combined with computational simulation are necessary for detailed explanation of the stability and high ionic conductivity of these RTILs.

\section{Acknowledgements}

The authors gratefully acknowledge Professor Charles L. Hussey of The University of Mississippi (USA) with deepest appreciation for supporting this work. 


\section{References}

[1] P. Walden, Bulletin de l’Académie Impériale des Sciences de St.-Pétersbourg (1914) 405.

[2] T. Tsuda, C.L. Hussey, Interface 16(1) (2007), 42 and references therein.

[3] J.S. Wilkes, M.J. Zaworotko, J. Chem. Soc., Chem. Commun. (1992) 965.

[4] For example, a) Ionic Liquids as Green Solvents: Progress and Prospects, ACS Symposium Series 856 (Eds. R.D. Rogers, K.R. Seddon), American Chemical Society, Washington, DC (2003); b) Ionic Liquids in Synthesis (Eds. P. Wasserscheid, T. Welton), Wiley-VCH, Weinheim (2003); c) Ionic Liquids III A and B: Fundamentals, Progress, Challenges, and Opportunities, ACS Symposium Series 901 and 902 (Eds. R.D. Rogers, K.R. Seddon), American Chemical Society, Washington, DC (2005);

d) Electrochemical Aspects of Ionic Liquids (Ed. H. Ohno) Wiley-Interscience, New Jersey (2005); e) P.J. Dyson, T.J. Geldbach, Metal Catalysed Reactions in Ionic Liquids, Springer, Netherlands (2006); f) Proceeding Series of the International Symposium on Molten Salts, I XIV, The Electrochemical Society, Inc., Pennington, New Jersey (1976 2006).

[5] For example, a) S. Takahashi, N. Koura, S. Kohara, M.-L. Saboungi, L.A. Curtiss, Plasmas \& Ions 2 (1999) 91; b) R. Hagiwara, Y. Ito, J. Fluorine Chem. 105 (2000) 221; c) C.F. Poole, J. Chromatogr., A 1037 (2004) 49; d) P.J. Scammells, J.L. Scott, R.D. Singer, Aust. J. Chem. 58 (2005) 155; e) J. Zhang, A.M. Bond, Analyst 130 (2005) 1132; f) H. Xue, R.Verma, J.M. Shreeve, J. Fluorine Chem. 127 (2006) 159; g) J.L. Anderson, D.W. Armstrong, G.-T. Wei, Anal. Chem. 78 (2006) 2892; h) M. Galiński, A. Lewandowski, I. Stępniak, Electrochim. Acta 51 (2006) 5567; i) R. Hagiwara, J.S. Lee, Electrochemistry 75 (2007) 23; j) K.E. Johnson, Interface 16(1) (2007) 38; k) K. Matsumoto, R. Hagiwara J. Fluorine Chem. 128 (2007) 317; l) S. Chowdhury, R.S. Mohan, J.L. Scott, Tetrahedron 63 (2007) 2363. 
[6] For example, a) R.V. Winsor, G.H. Cady, J. Am. Chem. Soc. 70 (1948) 1500; b) C. Simon, T. Cartailler, P. Turq, J. Chem. Phys. 117 (2002) 3772; c) K. Matsumoto, J. Ohtsuki, R. Hagiwara, S. Matsubara, J. Fluorine Chem. 127 (2006) 1339.

[7] For example, a) J. Fried, E.F. Sabo, J. Am. Chem. Soc. 76 (1954) 1455; b) R.F. Hirschmann, R. Miller, J. Wood, R.E. Jones, J. Am. Chem. Soc. 78 (1956) 4956; c) C.G. Bergstrom, R.M. Dodson, J. Am. Chem. Soc. 82 (1960) 3479; d) C.G. Bergstrom, R.T. Nicholson, R.M. Dodson, J. Org. Chem. 28 (1963) 2633; e) G.A. Olah, J. Welch, J. Am. Chem. Soc. 97 (1975) 208; f) N. Yoneda, J. Fluorine Chem. 105 (2000) 205; g) G.A. Olah, T. Mathew, A. Goeppert, B. Török, I. Bucsi, X.-Y. Li, Q. Wang, E.R. Marinez, P. Batamack, R. Aniszfeld, G.K. Surya Prakash, J. Am. Chem. Soc. 127 (2005) 5964.

[8] H. Moissan, Comptes rendus. 106 (1888) 547.

[9] G.H. Cady, J. Am. Chem. Soc. 56 (1934) 1431.

[10] N. Yoneda, T. Fukuhara, Molten Salts 45(1) (2002) 17 (in Japanese).

[11] For example, a) F. Hibbert, J. Emsley, in Advances in Physical Organic Chemistry, Vol. 26 (Ed. D. Bethell), Academic Press, San Diego, California, pp. 255-379 (1990); b) Y. Shodai, S. Kohara, Y. Ohishi, M. Inaba, A. Tasaka, J. Phys. Chem. A 108 (2004) 1127.

[12] K. Momota, Molten Salts 45(1) (2002) 42 (in Japanese) and references therein.

[13] I. Gennick, K.M. Harmon, M.M. Potvin, Inorg. Chem. 16 (1977) 2033 and references therein.

[14] Y. Saito, K. Hirai, K. Matsumoto, R. Hagiwara, Y. Minamizaki, J. Phys. Chem. B 109 (2005) 2942.

[15] R. Hagiwara, T. Hirashige, T. Tsuda, Y. Ito, J. Electrochem. Soc. 149(1) (2002) D1.

[16] R. Hagiwara, K. Matsumoto, Y. Nakamori, T. Tsuda, Y. Ito, H. Matsumoto, K. Momota, J. Electrochem. Soc. 150(12) (2003) D195.

[17] R. Hagiwara, T. Hirashige, T. Tsuda, Y. Ito, J. Fluorine Chem. 99 (1999) 1.

[18] R. Hagiwara, Y. Nakamori, K. Matsumoto, Y. Ito, J. Phys. Chem. B 109 (2005) 5445.

[19] K. Matsumoto, R. Hagiwara, Electrochemistry 73 (2005) 730. 
[20] R. Hagiwara, T. Nohira, T. Shimada, T. Fujinaga, S. Konno, T. Tsuda, ECS Trans. (2007), in press.

[21] C.J. Dymek, Jr., L.A. King, J. Electrochem. Soc. 132 (1985) 1375.

[22] C.L. Hussey, H.A. Øye, J. Electrochem. Soc. 131 (1984) 1621.

[23] C.L. Hussey, J.R. Sanders, H.A. Øye, J. Electrochem. Soc. 132 (1985) 2156.

[24] C.L. Hussey, J.R. Sanders, J. Electrochem. Soc. 134 (1987) 1977.

[25] H. Every, A.G. Bishop, M. Forsyth, D.R. MacFarlane, Electrochim. Acta 45 (2000) 1279.

[26] A. Noda, K. Hayamizu, M. Watanabe, J. Phys. Chem. B 105 (2001) 4603.

[27] M. Salanne, C. Simon, P. Turq, J. New Mat. Electrochem. Systems 9 (2006) 291.

[28] For example, a) H.L. Chum, R.A. Osteryoung, in Ionic Liquids (Eds. D. Inman, D.G. Lovering), Plenum Press, New York, pp. 407-423 (1981); b) C.L. Hussey, in Advances in Molten Salt Chemistry, Vol. 5 (Eds. G. Mamantov, C.B. Mamantov), Elsevier, Amsterdam, pp.185-230 (1983); c) G. Mamantov, C.L. Hussey, R. Marassi, in Techniques for Characterization of Electrodes and Electrochemical Processes ( Eds. R. Varma, J.R. Selman), John Wiley \& Sons, Inc., New York, pp. 471-513 (1991); d) C.L. Hussey, in Chemistry of Nonaqueous Solutions (Eds. G. Mamantov, A.I. Popov), VCH Publishers, Inc., New York, pp. 227-275 (1994); e) R.T. Carlin, J.S. Wilkes, in Chemistry of Nonaqueous Solutions, (Eds. G. Mamantov, A.I. Popov), VCH Publishers, Inc., New York, pp. 277-306 (1994); f) G.R. Stafford, C.L. Hussey, in Advances in Electrochemical Science and Engineering, Vol. 7 (Eds. R.C. Alkire, D.M. Kolb), Wiley-VCH, Weinheim, pp. 275-347 (2001).

[29] a) A.A. Fannin, Jr., D.A. Floreani, L.A. King, J.S. Landers, B.J. Piersma, D.J. Stech, R.L. Vaughn, J.S. Wilkes, J.L. Williams, J. Phys. Chem. 88 (1984) 2614; b) J.R. Sanders, E.H. Ward, C.L. Hussey, J. Electrochem. Soc. 133 (1986) 325 and 1526.

[30] K. Matsumoto, T. Tsuda, R. Hagiwara, Y. Ito, O. Tamada, Solid State Sci. 4 (2002) 23.

[31] M. Winter, WebElements periodic table of the elements - Scholar Edition, URL: http://www.webelements.com/webelements/scholar/properties/definitions/van-der-waals-radius.html 
[32] a) S. Tait, R.A. Osteryoung, Inorg. Chem. 23 (1984) 4352; b) K.M. Dieter, C.J. Dymek, Jr., N.E. Heimer, J.W. Rovang, J.S. Wilkes, J. Am. Chem. Soc. 110 (1988) 2722; c) C.J. Dymek, Jr., D.A. Grossie, A.V. Fratini, W.W. Adams, J. Mol. Struct. 213 (1989) 25.

[33] M. Salanne, C. Simon, P. Turq, J. Phys. Chem. B 110 (2006) 3504.

[34] R. Hagiwara, K. Matsumoto, T. Tsuda, Y. Ito, S. Kohara, K. Suzuya, H. Matsumoto, Y. Miyazaki, J. Non-Cryst. Solids 312-314 (2002) 414.

[35] K. Matsumoto, R. Hagiwara, Y. Ito. S. Kohara, K. Suzuya, Nucl. Instrum. Methods Phys. Res., Sect. B 199 (2003) 29.

[36] J.S. Wilkes, J.A. Levisky, R.A. Wilson, C.L. Hussey, Inorg. Chem. 21 (1982) 1263.

[37] K. Matsumoto, R. Hagiwara, R. Yoshida, Y. Ito, Z. Mazej, P. Benkič, B. Žemva, O. Tamada, H. Yoshino, S. Matsubara, Dalton Trans. (2004) 144. 
Table 1. TT and RH

Table 1

Melting points of conventional fluorohydrogenate salts consisting of cation and $\mathrm{F}(\mathrm{HF}) n^{-}$

\begin{tabular}{|c|c|c|c|c|c|c|}
\hline \multirow[t]{2}{*}{ Cations } & \multicolumn{4}{|c|}{ Number of HF ligand $(n)$} & \multirow[t]{2}{*}{ Note } & \multirow[t]{2}{*}{ Ref. } \\
\hline & 1 & 2 & 3 & 4 & & \\
\hline $\mathrm{Na}^{+}$ & $\sim 543^{\mathrm{a}}$ & - & 335 & 312 & & [13] \\
\hline $\mathrm{K}^{+}$ & $512^{\mathrm{b}}$ & $345^{b}$ & 339 & 345 & & {$[12,13]$} \\
\hline \multirow[t]{2}{*}{$\mathrm{Rb}^{+}$} & 483 & 336 & 325 & 305 & & [12] \\
\hline & 478 & 335 & 324 & 303 & & {$[13]$} \\
\hline \multirow[t]{2}{*}{$\mathrm{Cs}^{+}$} & 442 & 321 & 306 & $\sim 273$ & & [12] \\
\hline & 449 & 323 & 306 & - & & {$[13]$} \\
\hline $\mathrm{NH}_{4}^{+}$ & 400 & $321^{\mathrm{c}}$ & 299 & - & $\begin{array}{l}269 \mathrm{~K} \\
(n=2.2)\end{array}$ & {$[12]$} \\
\hline $\mathrm{N}\left(\mathrm{CH}_{3}\right)_{4}^{+}$ & - & 376 & - & - & $\begin{array}{l}\sim \mathrm{RT} \\
(n=3.2)\end{array}$ & {$[12]$} \\
\hline $\mathrm{P}\left(n-\mathrm{C}_{4} \mathrm{H}_{9}\right)_{4}{ }^{+}$ & 305 & $\sim 298$ & - & - & & [12] \\
\hline
\end{tabular}

a Decomposition; ${ }^{b}$ Electrolyte for $\mathrm{F}_{2}$ production; ${ }^{\mathrm{c}}$ Electrolyte for $\mathrm{NF}_{3}$ production. 
Table 2. TT and RH

Table 2

Physicochemical properties of heterocyclic ammonium fluorohydrogenate RTILs, XF(HF)2.3, at 298 $\mathrm{K}$

\begin{tabular}{|c|c|c|c|c|c|c|c|c|c|c|}
\hline \multicolumn{4}{|c|}{ Cations } & \multirow{2}{*}{$\begin{array}{l}\text { m.w. }{ }^{\mathrm{b}} \\
\left(\mathrm{g} \mathrm{mol}^{-1}\right)\end{array}$} & \multirow{2}{*}{$\begin{array}{l}\text { m.p. }{ }^{\mathrm{c}} \\
(\mathrm{K})\end{array}$} & \multirow{2}{*}{$\begin{array}{l}\operatorname{tg}^{\mathrm{d}} \\
(\mathrm{K})\end{array}$} & \multirow{2}{*}{$\begin{array}{l}\mathrm{d}^{\mathrm{e}} \\
\left(\mathrm{g} \mathrm{cm}^{-3}\right)\end{array}$} & \multirow{2}{*}{$\begin{array}{l}\eta^{\mathrm{f}} \\
(\mathrm{cP})\end{array}$} & \multirow{2}{*}{$\begin{array}{l}\sigma^{\mathrm{g}} \\
\left(\mathrm{mS} \mathrm{cm}{ }^{-1}\right)\end{array}$} & \multirow[t]{2}{*}{ Ref. } \\
\hline Type $^{\mathrm{a}}$ & $\mathrm{R} 1$ & $\mathrm{R} 2$ & R3 & & & & & & & \\
\hline A & $\mathrm{Me}$ & $\mathrm{H}$ & $\mathrm{Me}$ & 162 & 272 & - & 1.17 & 5.1 & 110 & [16] \\
\hline A & $\mathrm{Me}$ & $\mathrm{H}$ & $\mathrm{Et}$ & 176 & 208 & 148 & 1.13 & 4.9 & 100 & [15-18] \\
\hline A & $\mathrm{Me}$ & $\mathrm{H}$ & $n-P r$ & 190 & - & 152 & 1.11 & 7.0 & 61 & [16] \\
\hline A & $\mathrm{Me}$ & $\mathrm{H}$ & $n-\mathrm{Bu}$ & 204 & - & 154 & 1.08 & 19.6 & 33 & [16] \\
\hline A & $\mathrm{Me}$ & $\mathrm{H}$ & $n$-Pen & 218 & - & 158 & 1.05 & 26.7 & 27 & [16] \\
\hline A & $\mathrm{Me}$ & $\mathrm{H}$ & $n$-Hex & 232 & - & 157 & 1.00 & 25.8 & 16 & [16] \\
\hline A & $\mathrm{Me}$ & $\mathrm{Me}$ & $\mathrm{Et}$ & 190 & 237 & - & 1.10 & 6.8 & 56.9 & [19] \\
\hline A & $\mathrm{Me}$ & $\mathrm{H}$ & Allyl & 188 & - & - & 1.11 & 5.5 & 90 & [20] \\
\hline B & $n-\mathrm{Bu}$ & - & - & 136 & - & - & 1.09 & 25.0 & 37.0 & [20] \\
\hline B & Allyl & - & - & 120 & - & - & 1.12 & 5.3 & 82 & [20] \\
\hline $\mathrm{C}$ & $\mathrm{Me}$ & $\mathrm{Et}$ & - & 179 & $<145$ & - & 1.07 & 9.9 & 74.6 & [20] \\
\hline $\mathrm{C}$ & $\mathrm{Me}$ & $n-\operatorname{Pr}$ & - & 193 & $<145$ & - & 1.05 & 11.2 & 58.1 & [20] \\
\hline $\mathrm{C}$ & $\mathrm{Me}$ & $n-\mathrm{Bu}$ & - & 207 & $<145$ & - & 1.04 & 14.5 & 35.9 & [20] \\
\hline $\mathrm{C}$ & $\mathrm{Me}$ & $n$-Hex & - & 235 & - & - & 0.993 & 18.0 & 23.7 & [20] \\
\hline $\mathrm{C}$ & $\mathrm{Me}$ & Allyl & - & 191 & - & - & 1.05 & 8.5 & 78 & [20] \\
\hline $\mathrm{D}$ & $\mathrm{Me}$ & $\mathrm{Et}$ & - & 193 & 237 & 217 & 1.07 & 24.2 & 37.2 & [20] \\
\hline $\mathrm{D}$ & $\mathrm{Me}$ & $n-\operatorname{Pr}$ & - & 207 & - & 164 & 1.06 & 33.0 & 23.9 & [20] \\
\hline $\mathrm{D}$ & $\mathrm{Me}$ & $n-\mathrm{Bu}$ & - & 221 & - & 162 & 1.04 & 37.1 & 12.3 & [20] \\
\hline $\mathrm{D}$ & $\mathrm{Me}$ & Allyl & - & 205 & - & - & 1.06 & 16.7 & 63 & [20] \\
\hline $\mathrm{E}$ & $\mathrm{Me}$ & Allyl & - & 142 & - & - & 1.16 & 34.6 & 35 & [20] \\
\hline
\end{tabular}

${ }^{\mathrm{a} B a s i c}$ structures are depicted in Figure 4.

${ }^{\mathrm{b}}$ Molecular weight; ${ }^{\mathrm{c}}$ Melting point; ${ }^{\mathrm{d}}$ Glass transition temperature; ${ }^{\mathrm{e}}$ Density; ${ }^{\mathrm{f}}$ Viscosity; ${ }^{\mathrm{g}}$ Conductivity. 
Table 3. TT and RH

Table 3

Transport number of cations in EtMeIm+-based RTILs

\begin{tabular}{|c|c|c|c|c|c|}
\hline RTILs & $\mathrm{tEtMeIm}^{+}$ & Anions & $\begin{array}{l}\text { Temp. } \\
(\mathrm{K})\end{array}$ & Method & Ref. \\
\hline $\begin{array}{l}\mathrm{AlBr} 3-\mathrm{EtMeImBr} \\
\text { [AlCl} 3: 30 \sim 71 \mathrm{~mol} \% \text { ] }\end{array}$ & $0.76 \pm 0.02$ & $\begin{array}{l}\mathrm{Br}^{-}, \quad \mathrm{Br}(\mathrm{AlBr} 3)_{1}^{-}, \\
\mathrm{Br}\left(\mathrm{AlBr}_{3}\right)_{2}^{-}\end{array}$ & $333 \pm 2$ & $\mathrm{MH}$ & [24] \\
\hline $\begin{array}{l}\mathrm{AlCl}_{3}-\mathrm{EtMeImCl} \\
{\left[\mathrm{AlCl}_{3}: 30 \sim 50 \mathrm{~mol} \%\right]}\end{array}$ & $0.71 \pm 0.02$ & $\mathrm{Cl}^{-}, \mathrm{Cl}\left(\mathrm{AlCl}_{3}\right)_{1}^{-}$ & $298 \pm 3$ & $\mathrm{MH}$ & [23] \\
\hline $\begin{array}{l}\mathrm{AlCl}_{3}-\mathrm{EtMeImCl} \\
{\left[\mathrm{AlCl}_{3}: 34 \sim 48 \mathrm{~mol} \%\right]}\end{array}$ & $0.714^{\mathrm{a}}$ & $\mathrm{Cl}^{-}, \mathrm{Cl}\left(\mathrm{AlCl}_{3}\right)_{1}^{-}$ & 303 & $\mathrm{MH}$ & [21] \\
\hline $\begin{array}{l}\mathrm{AlCl}_{3} \text {-EtMeImCl } \\
{\left[\mathrm{AlCl}_{3}: 50 \mathrm{~mol} \%\right]}\end{array}$ & $0.70 \pm 0.02$ & $\mathrm{Cl}\left(\mathrm{AlCl}_{3}\right)_{1}^{-}$ & 366 & $\mathrm{MB}$ & [21] \\
\hline $\begin{array}{l}\mathrm{AlCl}_{3}-\mathrm{EtMeImCl} \\
{\left[\mathrm{AlCl}_{3}: 50 \sim 67 \mathrm{~mol} \%\right]}\end{array}$ & $0.71 \pm 0.02$ & $\begin{array}{l}\mathrm{Cl}\left(\mathrm{AlCl}_{3}\right)_{1}^{-} \\
\mathrm{Cl}\left(\mathrm{AlCl}_{3}\right)_{2}^{-}\end{array}$ & $301 \pm 2$ & $\mathrm{MH}$ & [22] \\
\hline EtMeImBF 4 & $0.54^{\mathrm{b}}$ & $\mathrm{BF}_{4}^{-}$ & 298 & PNMR & [26] \\
\hline EtMeImTfO & $0.6^{\mathrm{b}}$ & $\mathrm{TfO}^{-}$ & $303 \sim 403$ & PNMR & [25] \\
\hline EtMeImNTf $_{2}$ & $\begin{array}{l}0.5 \sim 0.6^{\mathrm{b}} \\
0.64^{\mathrm{b}}\end{array}$ & $\begin{array}{l}\mathrm{NTf}_{2}^{-} \\
\mathrm{NTf}_{2}^{-}\end{array}$ & $\begin{array}{l}303 \sim 403 \\
298\end{array}$ & $\begin{array}{l}\text { PNMR } \\
\text { PNMR }\end{array}$ & $\begin{array}{l}{[25]} \\
{[26]}\end{array}$ \\
\hline $\operatorname{EtMeImF}(\mathrm{HF})_{2.3}$ & $\begin{array}{l}0.44^{\mathrm{b}} \\
0.49^{\mathrm{b}}\end{array}$ & $\begin{array}{l}\mathrm{F}(\mathrm{HF})_{2}^{-}, \mathrm{F}(\mathrm{HF}) 3^{-} \\
\mathrm{F}(\mathrm{HF})_{1}^{-}, \mathrm{F}(\mathrm{HF})_{2}^{-} \\
\mathrm{F}(\mathrm{HF}) 3^{-}\end{array}$ & $\begin{array}{l}298 \\
298\end{array}$ & $\begin{array}{l}\text { PNMR } \\
\text { MD }\end{array}$ & $\begin{array}{l}{[14]} \\
{[27]}\end{array}$ \\
\hline
\end{tabular}

${ }^{\mathrm{a}}$ Mean value; ${ }^{\mathrm{b}}$ tEtMeIm $^{+}=D_{\mathrm{H} \text { (cation) }} /\left(D_{\mathrm{H}(\text { cation })}+D_{\mathrm{F} \text { (anion) })}\right.$.

MH: Modified Hittorf; MB: Moving Boundary; PNMR: Pulsed Gradient-field Spin Echo (PGSE) NMR; MD: Molecular Dynamics simulation; Tf: $\mathrm{SO}_{2} \mathrm{CF}_{3}$ 
Figure 1. TT and $\mathrm{RH}$
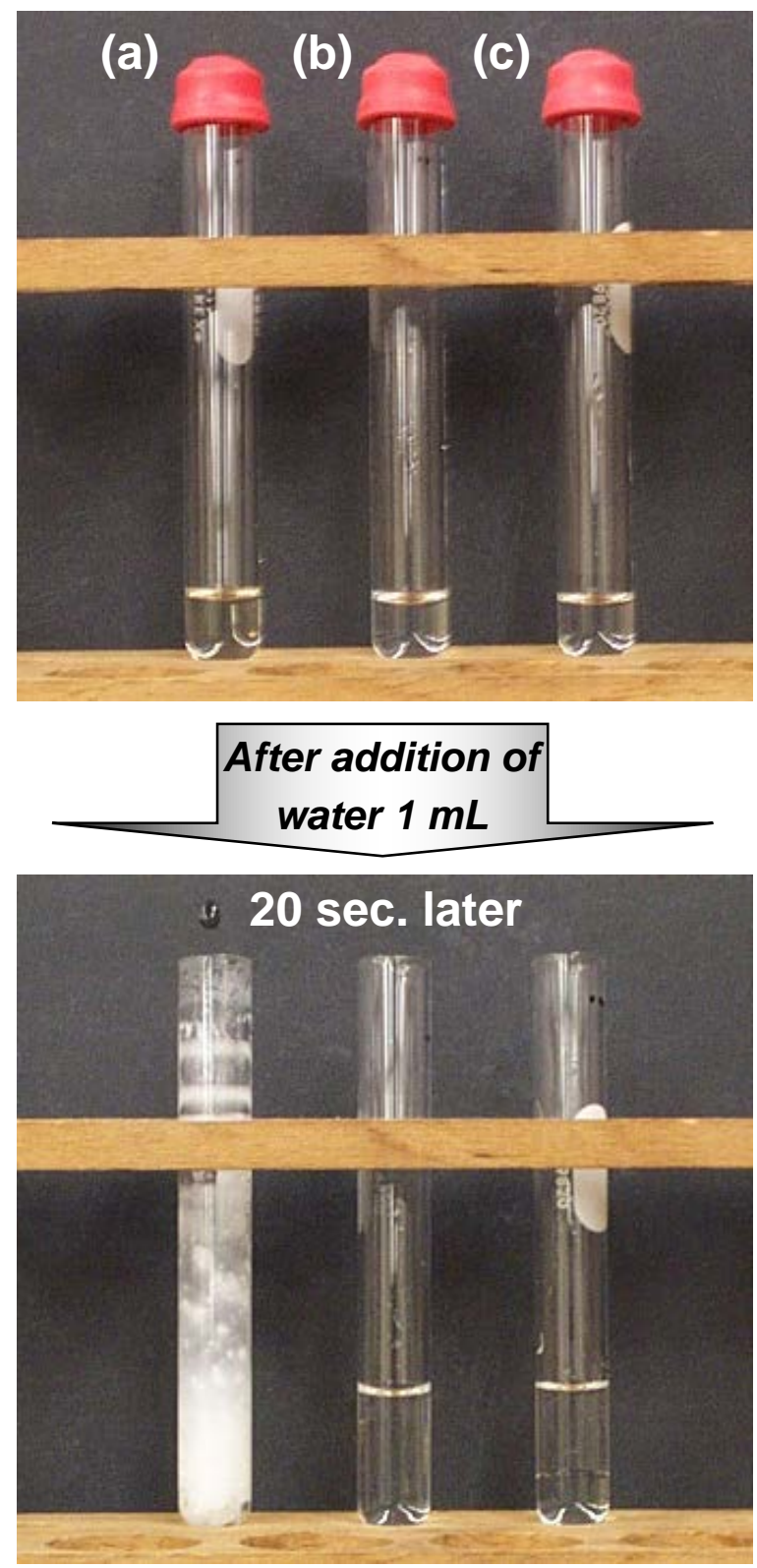
Figure 2. TT and $\mathrm{RH}$

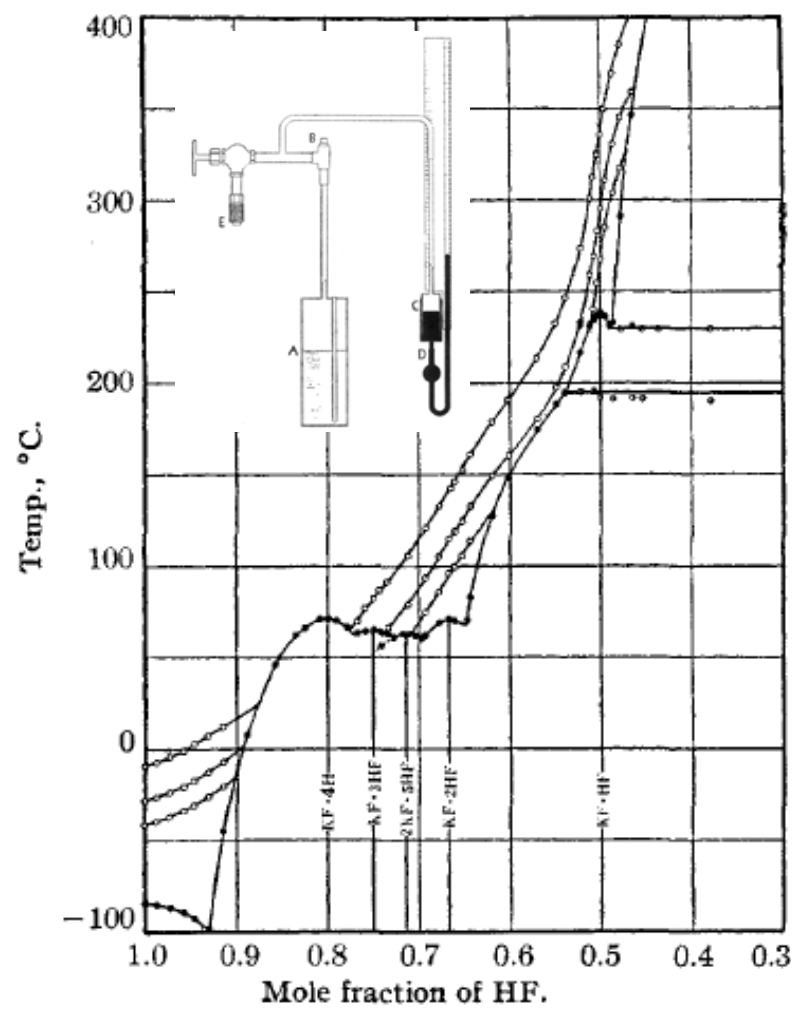


Figure 3. TT and $\mathrm{RH}$

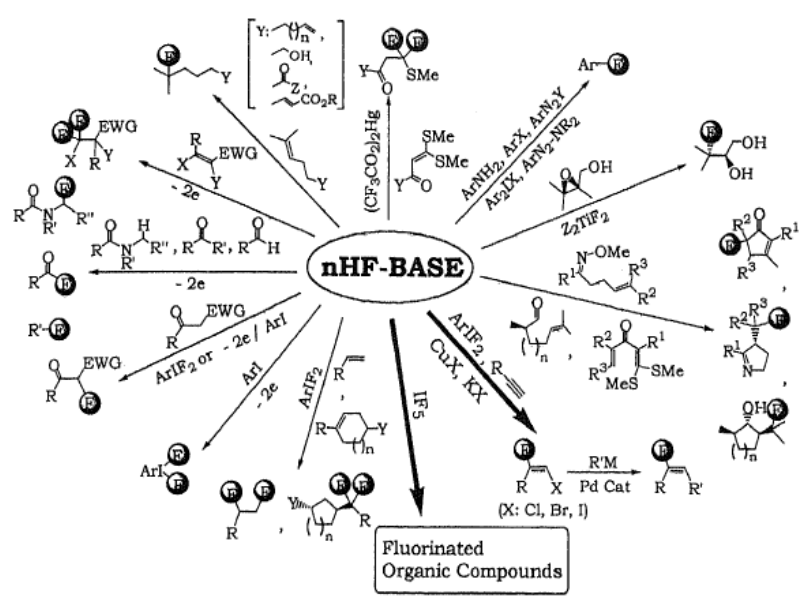


Figure 4. TT and $\mathrm{RH}$

\section{Cations}<smiles>[R1]n1cc[n+]([R2])c1</smiles><smiles>[R17][n+]1ccccc1</smiles>

\section{Anions}

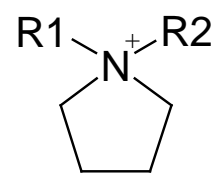

Imidazolium cation (A) Pyridinium cation (B) Pyrrolidinium cation (C)<smiles>[R1][N+]1([R2])CCCCC1</smiles><smiles>[R1][N+]1([R2])CCOCC1</smiles>

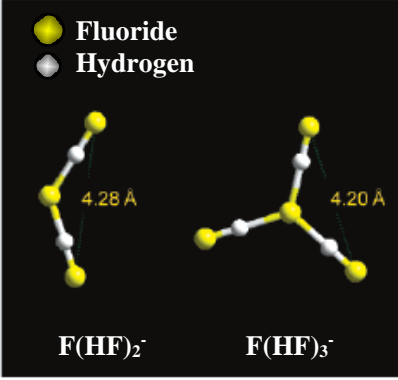

Piperidinium cation (D) Morphornium cation (E) 
Figure 5. TT and RH

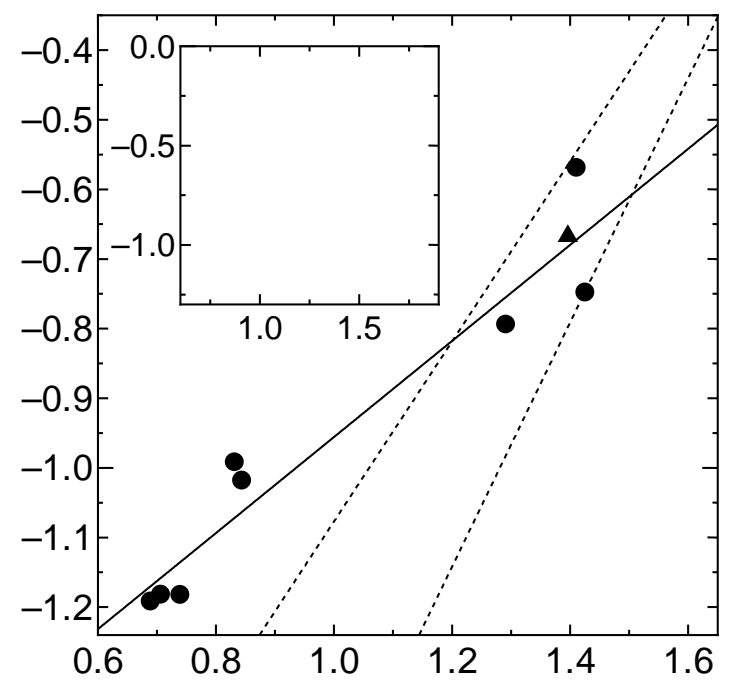



Figure 7. TT and $\mathrm{RH}$

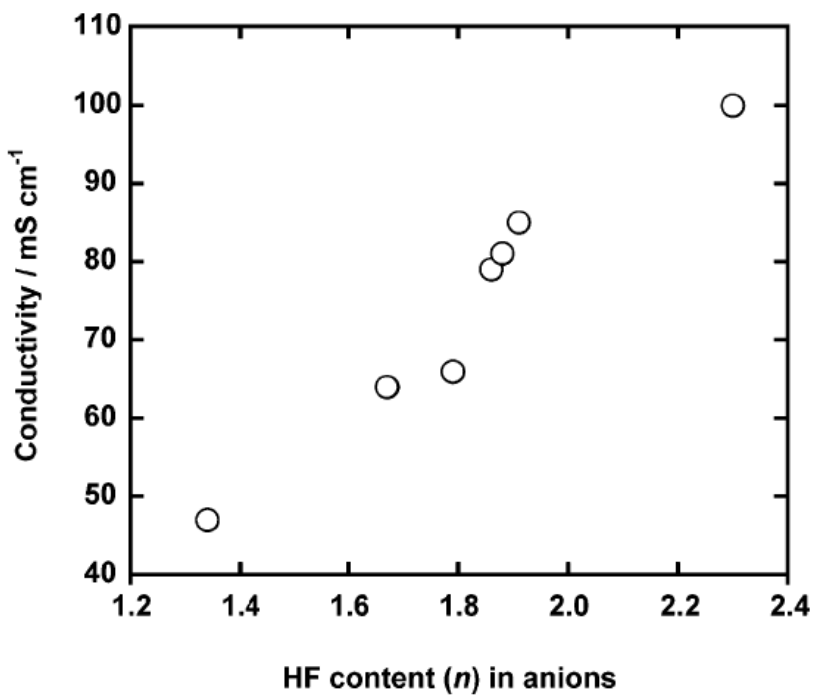


Figure 8. TT and RH

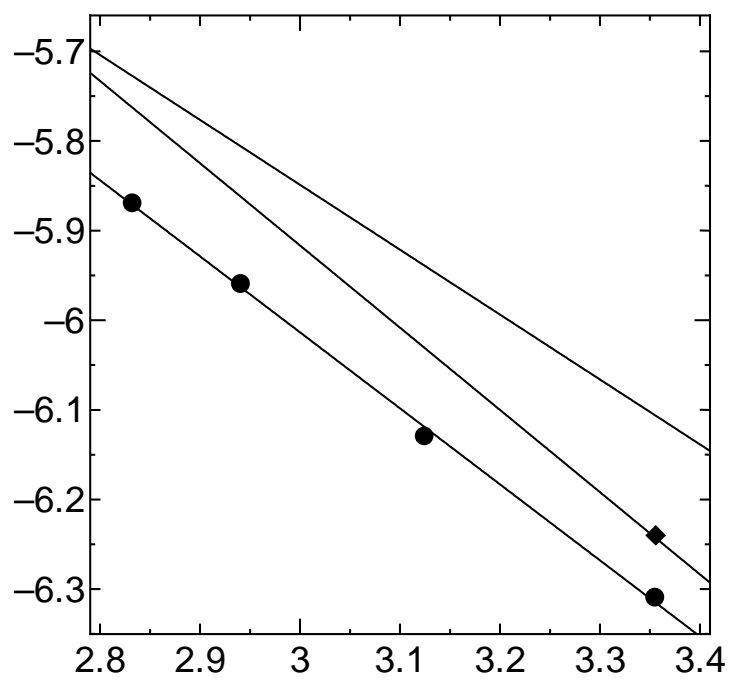



Figure 10. TT and RH

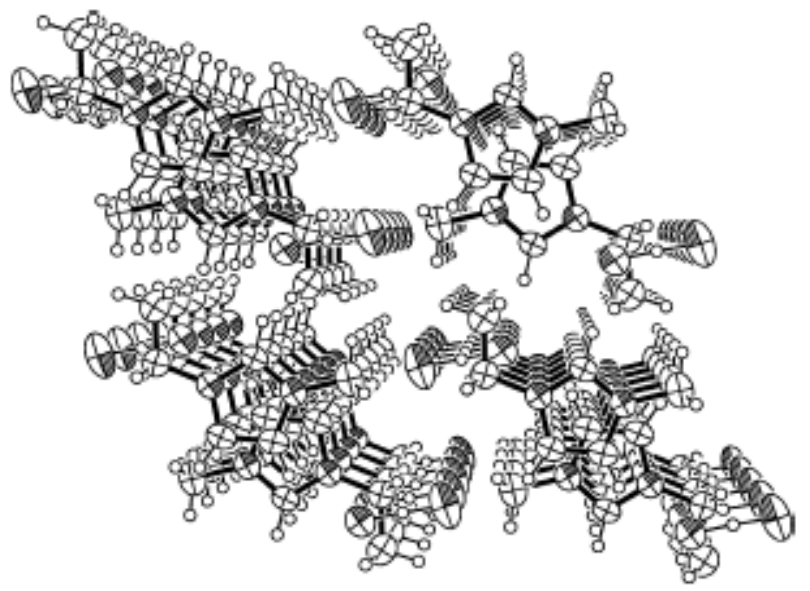


Figure 11. TT and RH

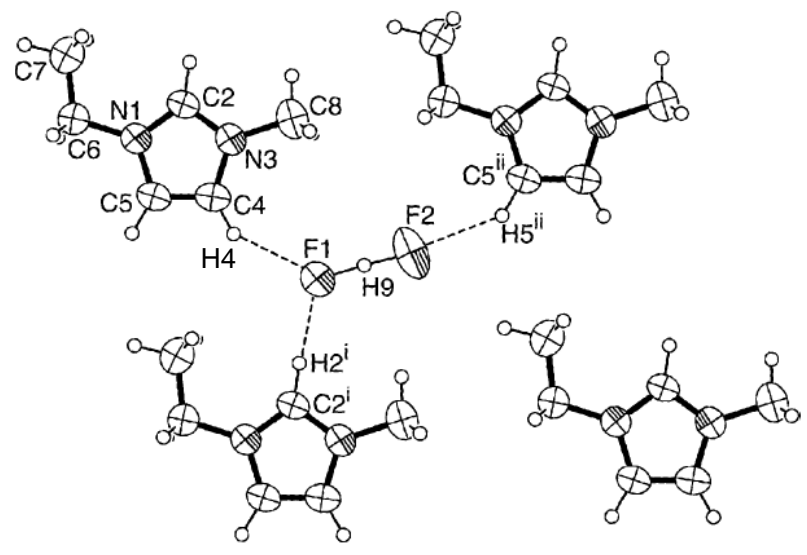


Figure 12. TT and RH

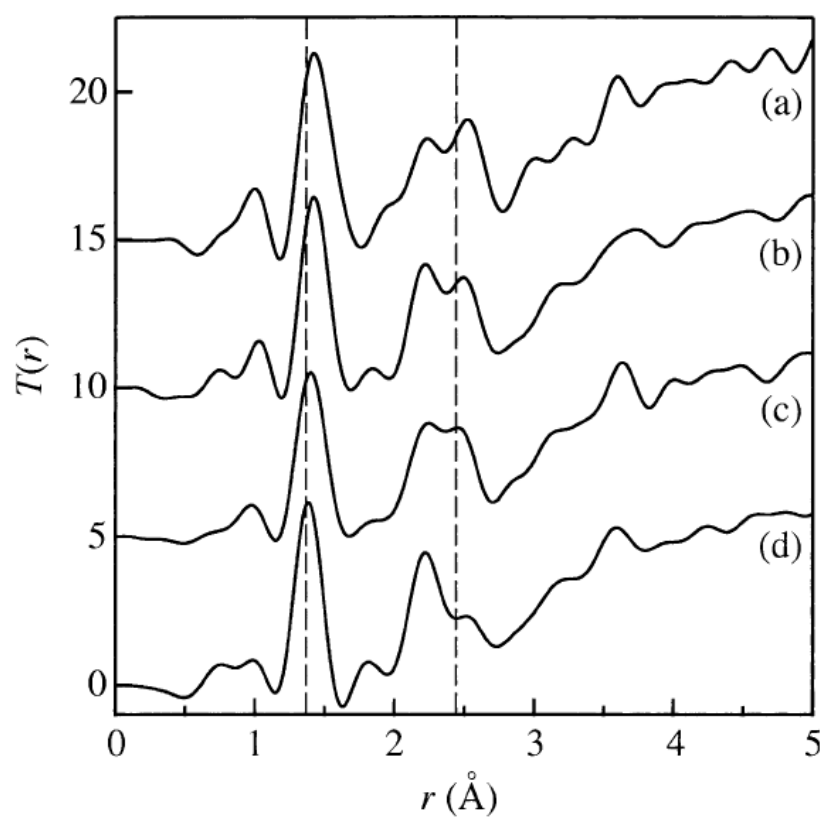


Figure 13. TT and RH
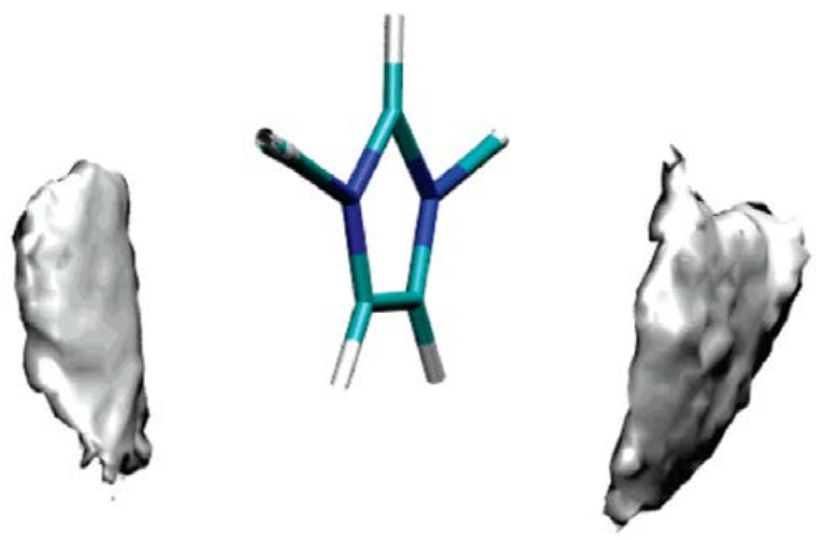
Figure 14. TT and RH

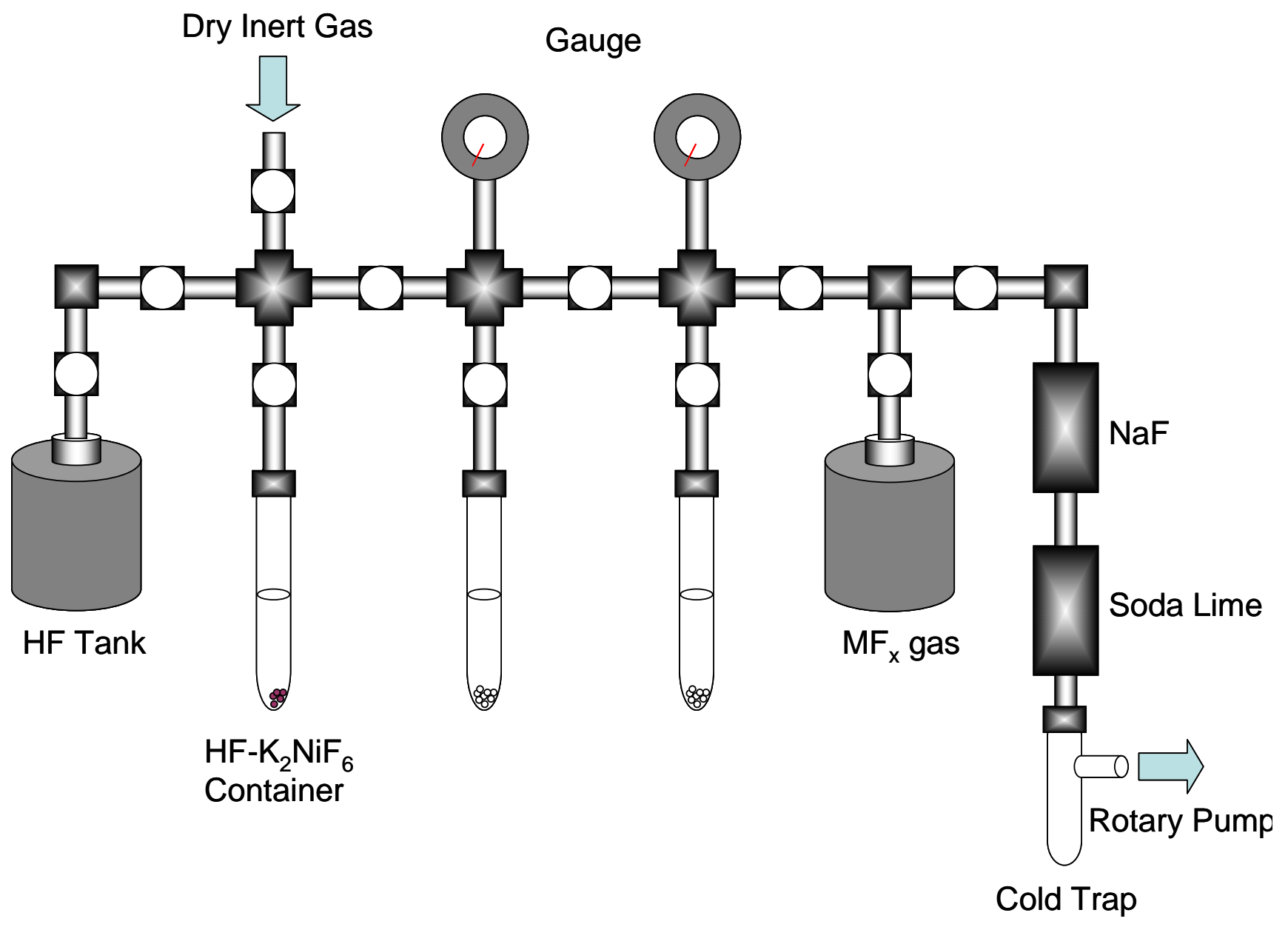




\section{Figure Captions}

Fig. 1. Photographs of (a) 60.0-40.0 mol \% $\mathrm{AlCl}_{3}-\mathrm{EtMeImCl}$; (b) EtMeImF(HF)2.3; (c) nBusMeNNTf $_{2}$ : (top) before the addition of water, and (bottom) after the addition of water.

Fig. 2. Phase diagram of KF-HF [9]. (inset) Apparatus used to study the KF-HF system [9].

Fig. 3. Example of fluorination reactions using HF-organic base solution [10].

Fig. 4. Basic structure of cations and anions of $\mathrm{XF}(\mathrm{HF})_{2.3 .} \mathrm{F}(\mathrm{HF})_{2}{ }^{-}$and $\mathrm{F}(\mathrm{HF})_{3}{ }^{-}$anions were obtained from ab initio molecular orbital calculation [14].

Fig. 5. Walden plot for fluorohydrogenated RTILs, XF(HF)2.3, constructed from Table 2.

imidazolium cation; ( $\mathbf{\Delta}$ ) pyridinium cation; ( o) pyrrolidinium cation; ( ) piperidinium cation; ( ) morphornium cation. (inset) Walden plot for low-viscous (< $100 \mathrm{cP})$ EtMeIm ${ }^{+}$-based RTILs with fluoroanions. The used data are summarized in reference [5i].

Fig. 6. A phase diagram of EtMeImF(HF)n $[1.0 \leq n<2.6][18]$.

Fig. 7. Conductivity of EtMeImF(HF)n RTIL at $298 \mathrm{~K}$ as a function of numbers of HF ligand [18].

Fig. 8. Arrhenius plot of self-diffusion coefficients of $\mathrm{F}(\mathrm{HF})_{n}{ }^{-}$estimated from molecular dynamics simulation. (Reconstructed Figure 4 in Ref. [27].) 
Fig. 9. Layered structure in EtMeImF(HF)1.0 viewed from a direction perpendicular to a $b$-axis [30].

Fig. 10. Perspective view of structure in EtMeImF(HF)1.0 along a $b$-axis direction [30].

Fig. 11. Plane configuration of EtMeIm ${ }^{+}$cation and $\mathrm{F}(\mathrm{HF})_{1}{ }^{-}$in $\operatorname{EtMeImF}(\mathrm{HF})_{1.0}$ [30].

Fig. 12. Total correlation functions, $T(r)$, of 1-alkyl-3-methylimidazolium fluorohydrogenates: (a) $n$ HexMeImF(HF)2.3; (b) $n-\operatorname{BuMeImF(HF)2.3;~(c)~EtMeImF(HF)2.3;~and~(d)~1-H-MeImF(HF)2.3~[34].~}$ Successive curves are displaced upward by 5 for clarity. Dashed lines are guides.

Fig. 13. Three-dimensional density of imidazolium ring centers around a given imidazolium. The density was estimated by molecular dynamics simulation [33]. The clouds show the site that is three times higher than the average density.

Fig. 14. A diagrammatic illustration of a vacuum line for RTIL synthesis using corrosive fluoride gas. 